\title{
Enfermedad de Tay Sachs
}

DRES.: FERNANDO NOVOA S. *, MARTA COLOMBO c. * JUAN CLERICUS E. *.

La cnfermedad de Tay Sachs es una afección heredodegenerativa del Sistema Nervioso Central cuya primera referencia se remonta a 1881 , año en que W. Tay describio las alteraciones oculares. Posteriormente B. Sachs en 1898 define el cuadro clínico en los siguientes términos:

"Enfermedad heredodegenerativa de la infancia y que se caracteriza por una tríada sintomática: detención de todos los procesos mentales; debilidad progresiva de todos los músculos del cuerpo, terminando en parálisis y ceguera rápidamente progresiva asociada a cambios en la mácula, Ia mancha rojo cereza y a atrofia óptica" (1).

Actualmente en base al progreso alcanzado por la bioquímica se ha logrado determinar que se trata de un error congénito del metabolismo de los lípidos.

Bloquímica. Es una enfermedad de depósito intraneuronal siendo el material acumulado un gangliosido, que según la clasificación de Svennerholm (2) correspondería al GMz. Este es un componente normal del Sistema Nervioso, constituyendo el 1-3\% del total de gangliosidos presentes en él, sin embargo, en esta enfermedad aumenta hasta alcanzar cifras del orden de1 $90 \%$. El sistema enzimático que degrada este GMz está constituido por las hexosaminidasas A y B, que sería el comprometido en esta afección, trayendo como consecuencia su acumulación (3).

Según la anormalidad bioquímica se pueden distinguir las formas de gangliosidosis $\mathrm{GM}_{2}$ (4), resumidas en la Tabla Nọ 1.

Genetica. Es heredada como autosómica recesiva, habiendo una especial incidencia en la población judía donde su frecuencia es de $12 \mathrm{x}$ 100.000 nacimientos, comparada con $0,2 \mathrm{x}$ 100.000 nacimientos en los no judíos (5).

\footnotetext{
* Servicio de Neuropsiquiatría. Hospital Manuel Arriarán.

* Deplu. Nutrición y Tecnología de los Alimentos. U. de Chile.
}

TABLA NO 1

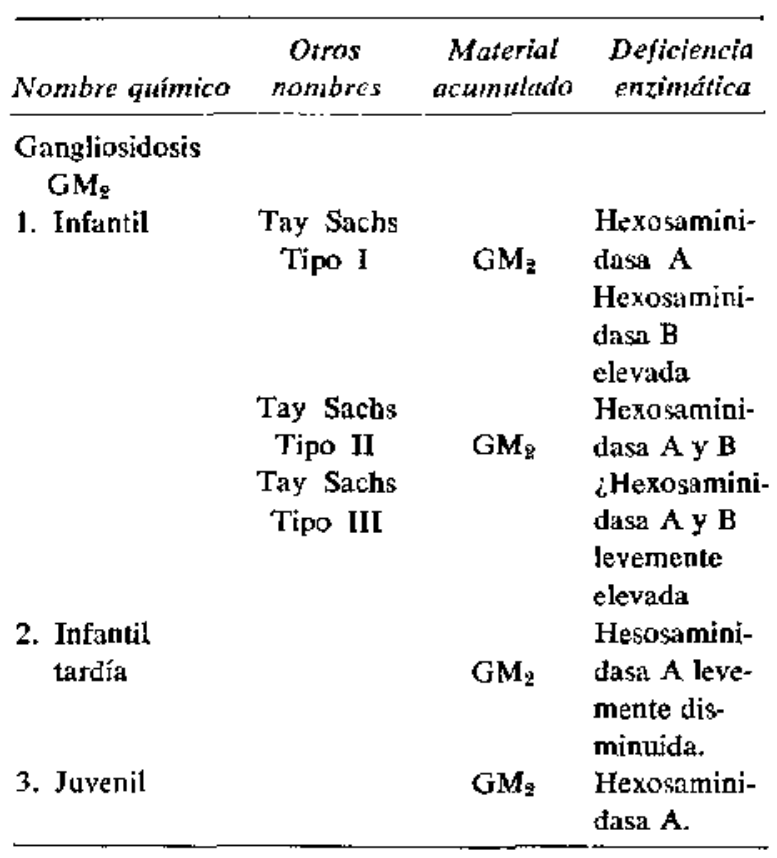

Cuadro Clinico. Generalmente estos niños tienen un desarrollo motor y psíquico normal basta los 5-6 primeros meses de vida, época en que aparece una detención del desarrollo que evoluciona a un grave deterioro. Habitualmente después del 1er. año de vida, presentan un marcado compromiso del estado general y nutritivo estando confinados a una vida vegetativa. Fallecen entre los 2 a 3 años después de la iniciación de los síntomas. Las manifestaciones iniciales más frecuentes son la incapacidad de seguir con la mirada y la pérdida de la capacidad de sostener la cabeza. Se consideran como característicos de esta enfermedad la respuesta anormal de sobresalto ante 
los estímulos sonoros y la ceguera precoz. Este último síntoma está en relación a una lesión retinal muy notoria que en el fondo de ojos da un aspecto típico de mancha rojo cereza en la región de la mácula. En etapas más avanzadas de la en. fermedad, se agregan convulsiones y un rápido crecimiento de la circunferencia craneana acompañado de un llamativo aumento en el peso de la cabeza $(1,5)$.

Diagnostico. El diagnóstico se basa en el cuadro clínico descrito siendo de especial relevancia el examen de fondo de ojos que revela la presencia de la mancha rojo cereza en el $90 \%$ de Jos pacientes, Desde el punto de vista bioquímico se puede confirmar determinando la actividad de la enzima hexosaminidasa $A(6)$, y el aumento de GMz en biopsia rectal $y / 0$ cerebral. Otros hallazgos que aún no tienen explicación serían e? aumento de transaminasas y deshidrogenasa láctica del suero, con una gran reducción de la actividad de la aldolasa fructosa 1 fosfato $(5,7)$.

Tratamiento. Hasta la fecha sólo se dispone de tratamiento sintomático, siendo imposible modificar el curso irremediablemente fatal de la enfermedad. Sólo se les puede of recer a parientes de pacientes con la enfermedad de Tay Sachs el diagnóstico prenatal por la determinación de la enzima hexosaminidasa $A$ en cultivo de células amnióticas (8).

En cuanto al consejo genético, es preciso dar a conocer a los padres que se trata de una afección que se hereda en forma autosómica recesiva. Los heterozigotos pueden ser detectados mediante la determinación de hexosaminidasa $\mathrm{A}$, en suero, lágrimas o saliva $(6,9)$.

\section{CASOS CLINICOS}

\section{CASO 1. S. A. D.}

Ficha 203772 (Hospital Manuel Arriarán). Paciente de sexo femenino, primera hija de padres saros, sin consanguinidad. Sin ancestro judío. Antecedentes de embarazo, parto y desarrollo psicomotor hasta los 5 meses de edad normales. En esta época la madre nota que la niña deja de sostener la cabeza. En el transcurso de algunos meses impresiona quedar ciega, sin mantener ningún contacto con el medio, persistiendo sólo una vida vegetativa. En la épaca de consulta, a los 8 meses de edad, existía una leve hipertonía, que evoluciona a una marcada rigidez generalizada que se mantuvo hasta la fecha de su fallecimiento a los 2 años 5 messs. Durante sus hospitalizaciones se comprobó una marcada respuesta de sobresalto frente a los ruidos y la aparición de crisis convulsivas especialmente segmentarias que comprometían indistintamente las extremidades derechas o izquierdas.
La circunferencia craneana aumentó progresivamente de tunaño Jlegando a los $50 \mathrm{~cm}$. en el momento de fallecer.

Fondo de ojos: ambas máculas se aprecian de color rojo cerezis sobrc fondo retinal blanquecino.

Hígado $y$ bazo dentro de límiles normales.

EEG: ritmo lento, difuso, tipo delta de gran amplitud. Puntas agudas y simétricas (31-Marzo-1970) LCR: químico y citológico normal.

Radiografia de cráneo: Macrocefaliá, Suturas separadas.

Biopsia rectal: en la submucosa se observan células glanglionares cuyo citoplasma contiene abundantes inclusiones redondeadas. La imagen histológica es compatible con el diagnóstico de enfermedad de Tay Sachs. (Dr. Oscar Brunser).

Exámenes de rutina normales.

Autopsia: Aparte de los signos correspondientes a ut estado de caquexia avanzada, las alteraciones más llamativas se encontraron en el cerebro. El órgano era de color amarillo con una consistencia francamente aumentada. Peso: J.330 grs., lo cual es muy superior al correspondiente para la edad. La histología reveló neuronas hinchadas con citoplasma de aspecto hialino (Dr. José Manuel Rubio).

\section{CASO 2.- L. A. D.}

Ficha 276533 (Hospital Manuel Arriarán). Paciente de sexo masculino, hermano del Caso 1, que tiene el antecedente de embarazo, parto y desarrollo psicomotor hasta los 4 meses de edad normales. En esta época la madre nota una pérdida progresiva de las funciones adquiridas. Precozmente deja de seguir con la mirada, paralelamente pierde la capacidad de sostener la cabeza y de reaccionar con sonrisa ante la vecindad de la madre. En el transcurso de meses disminuye la actividad motora, el llanto, y desaparece el reflejo de succión. Presenta marcado sobresalto ante estímulos sonoros. Alrededor del año de edad se agtegan convulsiones especialmente focales, comprometiendo en forma alternada el hemicuerpo derecho o izquierdo. El tono, que a) momento de consulta, a los 11 meses de edad, estaba disminuido, evoluciona hacia una mareada hipertonía generalizada.

Cuadros respiratorios a repetición.

La circunferencia craneana a los 11 meses de edad era de $45 \mathrm{~cm}$., a los 13 meses es de $471 / 2 \mathrm{~cm}$.

Fondo de ojos: papilas algo pálidas. En ambas máculas se aprecia mancha rojo cereza rodeada de zona de retina pálida.

Hígado y bazo dentro de límites normales.

\section{CASO 3.- E. L. L.}

Ficha 264459 (Hospital Manuel Arriarán). Paciente de sexo masculino, primer hijo de padres sanos, sin consanguinidad. Sin ancestro judío. Antecedentes de embarazo, parto y desarrollo psicomotor hasta tos $4 \mathrm{me}$ - 
ses de edad normales. En esta época se nota un deterioro progtesivo: deja de seguir con la mirada y sostener la cabeza, no se intercsa en los objetos y existe marcado sobresalto con los ruidos. Desde los 8 meses de cdad se agregan espasmos masivos. En el examen, a los 10 meses de edad, se aprecia hipotonia con hiperreflexia osteotendinosa.

Circunferencia craneana: $49 \mathrm{~cm}$. a los 10 meses de edad.

Fondo de ojos: papilas nomales. En zona blanquecina de retina se aprecia mấcula de aspecto rojo cereza.

No se palpa higado ni bazo.

EEG.: Concordante con hipsarritmia.

LCR.: Químico y Citológico normal.

Radiografía de cráneo: Macrocefalia.

Biopsia rectal: Se observan células de los plexos mesentéricos hiechadas y vacuoladas (Dr. José Manuel Rubio).

Exámenes de rutina: normales.

El niño faljece en su domicilio a los 15 meses de edad. No se practica autopsia.

\section{CASO 4.- R. P. P. (Fígura Nọ 1).}

Ficha 278163 (Hospital Manuel Arriarán). Paciente de sexo masculino, segundo hijo de padres sanos, sin consanguizidad. Sin ancestro judio. Antecedentes de embarazo, parto y desarrollo psicomotor hasta los 7 meses de edad nomales.

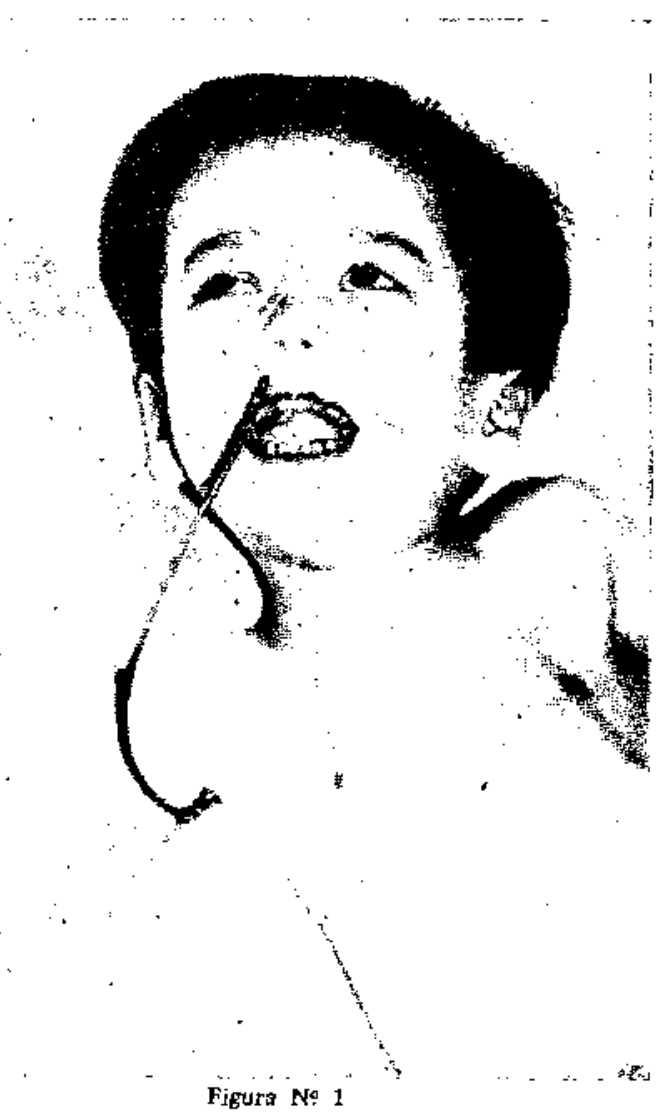

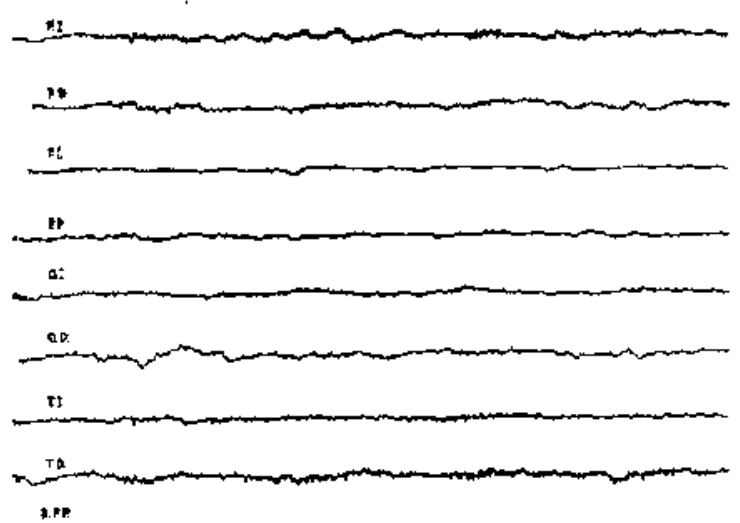

Figura Nợ 2

En esta época la madre le nota en forma ptogresiva menor actividad, deja de seguir objetos con la mirada y no sostiene la cabeza. Consulta médico quîn sospecha una hidrocefalia por tener un perímetro craneano aumentado para su edad. Se practicó neumorncefalografía que demostró un sistema ventricular de forma y tamaño normales. Posteriormente el niño continúa deteriorándose, desaparece el reflejo de succión y se aptecia marcado sobresalto ante los estímulos sonoros. Desde los 14 meses presenta espasmos masivos que son rebeldes al tratamiento habitual.

Se agregan cuadros respiratorios a repetición.

La circunferencia craneana crece en forma paulatina hasta llegar a los $571 / 2 \mathrm{~cm}$, a $\operatorname{los} 2$ años de edad (edad actual).

Fondo de ojos: mancha rojo cereza en mácula nodeada de halo de retina pálida en ambos ojos.

Hígado y bazo dentro de límites normales.

EEG: difusamente lento e irregular. (Figura N9 2).

LCR: Qúrtrico y Citológico normal.

Radiograffa de cráneo; Macrocefalia, suturas separadas.

Exámenes de rutina: normales.

Comentarjo. Las enfermedades degenerativas del Sistema Nervioso Central constituyen un grupo heterogéneo, siendo la mayoría genéticamente, y por lo tanto probablemente, químicamente determinadas. Tienen habitualmente de común, el afectar a niños que impresionan como normales en todo aspecto durante los primeros meses de vida (10), y un mismo resultado final: el niño pierde las habilidades motoras e intelectuales adquiridas, se presentan crisis convulsivas rebeldes a tratamientos, llegando en etapas terminales a mantenerse sólo con vida vegetativa, La muerte sobreviene por la caquexia y complicaciones respiratorias agregadas (1). Formando parte de este conglomerado se encuentran los errores congénitos del metabolismo de los lípidos, uno de Ios cuales está constituido por las gangliosidosis GMs, que es el que presentan nuestros 4 pacientes, quienes además, han tenido una evolución concordante en todo con los conceptos anteriores. 


\begin{tabular}{|c|c|c|c|c|}
\hline Casos clinicos & S. A. D. & L. A. D. & E. L.L. & R.P.P. \\
\hline Edad de comienzo & 5 meses & 4 meses & 4 meses & 7 meses \\
\hline $\begin{array}{l}\text { Antecedentes fami- } \\
\text { liares }\end{array}$ & Positivo & Positivo & Negativo & Negativo \\
\hline Motivo de consulta & Retraso psicomotor & Amaurosis & Retraso Psicomotor & Hidrocefalia \\
\hline $\begin{array}{l}\text { Hiper-respuesta a } \\
\text { ruidos }\end{array}$ & Presente & Presente & Presente & Presente \\
\hline Convulsiones & $\begin{array}{l}\text { Focalcs a derecha } \\
\text { o izquierda }\end{array}$ & $\begin{array}{l}\text { Focales a derecha } \\
\text { o izquierda }\end{array}$ & Espasmos masivos & Espasmos masivos \\
\hline Macrocefalia & Presente & Presente & Presente & Presente \\
\hline $\begin{array}{l}\text { Mancha rojo cereza } \\
\text { en fondo de ojo }\end{array}$ & Presente & Presente & Presente & Presente \\
\hline Amaurosis & Presente & Presente & Presente & Presente \\
\hline E. E. G. & $\begin{array}{l}\text { Lentitud difusa, pun- } \\
\text { tas agudas difusas }\end{array}$ & Lentitud difusa & Hipsarritmia & Lentitud difusa \\
\hline $\begin{array}{l}\text { Hepatoesplenome- } \\
\text { galia. }\end{array}$ & Ausente & Ausente & Ausente & Ausente \\
\hline
\end{tabular}

Tal como queda implícito en el nombre gangliosidosis $\mathrm{GMz}$, el factor común en este grupo de afecciones es el aumento excesivo del gangliosido GM: intrancuronal (11). Se distinguen diversos tipos, que entre otros aspectos se pueden diferenciar principalmente por la edad de comienzo de la sintomatología. Siendo enfermedades infrecuentes, la más común de ellas es la enfermedad de Tay Sachs, cuya sintomato'ogía se inicia en el período infantil, antes de los 8 meses de edad. (5). Este primer aspecto, imprescindible para sustentar el diagnóstico, junto a otros dos que son la lesión típica del fondo de ojos, con ceguera, y la respuesta de sobresa'to ante ruidos leves, son los que nos han orientado hacia el diagnóstico (11). Cabe destacar que la mancha rojo cereza del fordo de ojo que presenta el $90 \%$ de los pacientes, pucde encontrarse también en la enfermedad de Nieman Pick, de la cual se puede diferenciar fácilmente por la hepatoesplenomegalia, que es hallazgo constante en esta última (1). La trombosis đe la arteria central de la retina también tiene un aspecto de mancha rojo cereza en la mácula, pero se acompaña de otras alteraciones en el fondo de ojos y*el cuadro clínico es claramente diferente.

Clásicamente se acepta la existencia de un rápido deterioro de estos pacientes, que en el transcurso de algunos meses los ccnfina a una existencia vegetativa, evolución que hemos podido apreciar en todos nuestros enfermos (10). La macrocefalia que generalmente se presenta en el $2^{0}$ año de vida puede erróneamente orientar hacia un sindrome de hipertensión endocraneana en un niño que se deteriora en forma progresiva. El no valorizar otros elementos del cuadro clínico puede llevar a la práctica de exámenes innecesarios para establecer un diagnóstico, tal como sucedió en el caso 4. Las crisis convulsivas son constantes en etapas avanzadas de la enfermedad. Se caracterizan por ser rebeldes a los tratamientos habitua'cs, afirmación que hemos podida comprobar en nuestros casos.

La muerte se produce antes de los 4 anios de edad tal como ha ocurrido en 2 de nuestros enfermos.

Corrientemente se acepta que la enfermedad de Tay Sachs tiene una incidencia francamente mayor en individuos de raza judía (4). Esta característica no se ha confirmado en nuestra experiencia, ya que ninguno de nuestros 4 pacientes tiene ancestro judio.

\section{RESUMEN}

Se presentan 4 pacientes portadores de la enfermedad de Tay Sachs. Se analiza el cuadro clinico con sus etementos característicos que permite formular el diagnóstico con basiante certeza.

\section{SUMMARY}

Four patients with Tay Sachs. Disease are discussed. The clinical picture with its characteristic features is analyzed.

\section{REFERENCIAS}

1.-Freeman John M., Mc Khann Guy M. "Degenerative Disease of the Central Nervous System". Advances in Pediatrics. 16: 121, 1969. 
2.-Svennerhoim L. "Gangliosides". J. Lip. Res. 5: 145, 1964.

3.-Okada S., O'Brien J. S. "Tay Sachs Disease: Generalized Absence of a Beta D-N Acetylbexosaminidase Component". Science 165: 698, 1969.

4.-Wilson John. "Investigation of Degenerative Diseases of the Central Nervous System". Arch. Dis. Childh. 47: 163, 1972 .

5.-Davison A. N. "Applied Neurochemistry". Pág. 410. Blackwell Scientific Publications, 1968.

6.-O'Brien J., Okada S., Chen A., Fillerup D. "Tay Sachs Disease". New Engl. J. Med. 283: 15, 1970.

7.-Volk B. W., Aronson S, M., Saifer A. "Fructose 1 Phosphate Aldolase Deficiency in Tay Sachs Disense". Am. J. Med, 36: 481, 1964.

8.- Howell R. Rodney. "Prenatal Diagnosis in the Prevention of Handicapping Disorders". Ped. Clin. N. A. 20: 141, 1973.

9.- Singer Jack, D. "Hexosaminidase A in Tears and Saliva for Rapid Identification of Tay Sachs Disease and its Carriers". The Lancet Nov. 17: 1116, 1973.
10.-Ford Frank $\boldsymbol{R}$. "Enfermedades del Sistema Nervioso en la Infancia y Adolescencia". Pág. 594. Editorial La Médica, 1966.

11.-Brett E. M., Ellis R. B., Haas L., Ikonne J. U., Lake B. D., Patrick A. D., Stephens R. Late Onset GM $_{\mathbf{z}}$ Gangliosidosis". Arch. Dis. Childh. 48: 775, 1973.

12.- Ockerman P. A. "Lysosomal Enzymes in Juvenile Amaurotic Idiocy". Acta Ped. Scand. 57: 537, 1968.

13.-Rosner F., Weisfogel $G$., Feinerman A. "Infantile Amaurotic Familial Idiocy". J. A. M. A. 205: 165, 1968.

14.-Volk B., Wallace B., Sihneck L. "Late Infantile Amaurotic Idiocy". Arch. Path. 78; 483, 1964.

15.-Giorgi P. L., Paci A., Ciccarelli M. "An Extra Chromosome in a case of Tay Sachs Disease with Additional Abnormalities". Helv. Paed. Acta. 22: 28, 1967.

16.-Misra P. K., Sethi V. K., Ramchand S. "Tay Sachs Disease". Indian J. Ped. 35: 529, 1968.

17.-Navon R., Padeh B. "Urinary test for Tay Sachs Genotypes". J. Pediatrics. 80: 1026, 1972.

\section{CLINICA DE ENFERMEDADES RESPIRATORIAS INFANTILES "GRAGHER"}

Teresa Salas 851 - Fono 41764 - Santiago (altura 1.250 de José Miguel Infante)

Ofrece a los Sres. Médicos:

Estudio y tratamiento integral de Afecciones Broncopulmonares.

EXIMENES DE LABORATORIO:

1.-BACTERIOLOGIA BAC. KOCH, CULTIVO Y RESISTENCIA.

2.- TEST DE PRECIPITINAS.

3.- INMUNOGLOBULINAS.

4.- SECRECION FARINGEA Y CULTIVO EXPECTORACION.

5.-AUTOVACUNAS.

Test de Alergenos completos (Center Laboratories Inc. USA.) - Kinesioterapia - Nebulizaciones - Stock Vacunas - Hiposensibilización. 